\title{
Adverse Events in Giant Cell Arteritis and Rheumatoid Arthritis Patient Populations: Analyses of Tocilizumab Clinical Trials and Claims Data
}

\author{
Sara Gale $\cdot$ Huong Trinh · Katie Tuckwell - Neil Collinson • \\ John H. Stone - Khaled Sarsour · Jinglan Pei · Jennie Best • \\ Christine Birchwood · Shalini V. Mohan
}

Received: November 6, 2018 / Published online: February 1, 2019

(c) The Author(s) 2019

\section{ABSTRACT}

Introduction: The safety profile of tocilizumab (TCZ) in patients with rheumatoid arthritis (RA) is well established. TCZ was approved to treat giant cell arteritis (GCA) in 2017 in the USA and Europe, and its safety profile in patients with GCA continues to be defined. The objective of this analysis was to examine incidence rates (IRs) of adverse events of special interest (AESI) occurring during the TCZ clinical development program and in healthcare claims data in patients with GCA or RA.

Methods: TCZ-naïve patients with GCA or RA were identified in the MarketScan administrative healthcare claims database. TCZ-treated patients with GCA from the GiACTA trial and TCZ-treated patients with RA from pooled clinical trial data were analyzed. The IRs of AESI (AESI IRs) were calculated for all cohorts. In the

Enhanced digital features To view enhanced digital features for this article go to https://doi.org/10.6084/ m9.figshare.7584197.

S. Gale $(\bowtie) \cdot$ H. Trinh $\cdot$ K. Tuckwell $\cdot$ K. Sarsour · J. Pei · J. Best - C. Birchwood · S. V. Mohan Genentech, Inc, South San Francisco, CA, USA e-mail: gale.sara@gene.com

N. Collinson

Roche Products, Ltd, Welwyn Garden City, UK

J. H. Stone

Massachusetts General Hospital, Boston, MA, USA claims cohorts, risks of AESI were estimated using Poisson regression.

Results: TCZ-naïve claims cohorts comprised 4804 patients with GCA [mean (standard deviation) age 73.4 (9.8) years; follow-up 3.9 (3.1) years] and 15,164 patients with RA [age 60.3 (8.2) years; follow-up, 4.5 (2.8) years]. TCZtreated clinical trial cohorts comprised 149 patients with GCA [age 69.5 (8.4) years; exposure approx. 138 patient-years (PY)] and 7647 with RA [age 52 (12.6) years; exposure approx. 22,394 PY]. The IRs of infections, stroke, malignancies, myocardial infarction, and gastrointestinal perforations in the GCA claims cohort exceeded those in the RA claims cohort; the risk of AESI (adjusted for age and glucocorticoid use) was higher in patients with GCA than in those with RA. Similar patterns to the claims cohorts in terms of the AESI IRs were observed in clinical trial cohorts, although the number of events was limited in the GCA trial cohort.

Conclusion: Higher IRs of AESI were observed in patients with GCA versus those with RA in both TCZ-naïve and -treated cohorts. Differences in underlying disease, age, and glucocorticoid use may influence AESI incidence, irrespective of intervention.

Funding: This study was funded by F. Hoffmann-La Roche Ltd and Genentech, Inc. Article processing charges were funded by F. Hoffmann-La Roche Ltd. 
Plain Language Summary: Plain language summary is available for this article.

Keywords: Giant cell arteritis; Rheumatoid arthritis; Rheumatology; Safety; Tocilizumab

\section{PLAIN LANGUAGE SUMMARY}

This analysis characterizes the safety profile of tocilizumab (TCZ) in patients with giant cell arteritis (GCA) by comparing the incidence rates (IRs) of adverse events of special interest (AESI) between cohorts of patients with GCA and cohorts of patients with rheumatoid arthritis (RA). Four cohorts of patients were evaluated: (1) TCZ-naïve patients with GCA in a US healthcare claims database, (2) TCZ-naïve patients with RA in a US healthcare claims database, (3) TCZ-treated patients with GCA from the GiACTA trial, and (4) TCZ-treated patients with RA from a pooled trial population. In the TCZ-naïve patient cohorts, patients with GCA were at greater risk of AESI than patients with RA. Similar patterns were found in the TCZ-treated patients cohorts, although the number of events was limited by the smaller number of patients with GCA from the GiACTA trial compared with the number of patients with RA in the pooled clinical trial population. These findings highlight that differences in the underlying disease, age, and glucocorticoid use may influence the occurrence of safety events in patients with GCA versus those with RA, whether or not they receive TCZ.

\section{INTRODUCTION}

Giant cell arteritis (GCA) is the most common form of systemic vasculitis, occurring most frequently in women, people of Northern European descent, and individuals aged $\geq 50$ years [1-5]. Symptoms of GCA comprise headache, jaw and limb claudication, scalp and tongue necrosis, polymyalgia rheumatica, visual impairment, and elevated markers of inflammation, including erythrocyte sedimentation rate and C-reactive protein $[1,2]$. Permanent vision loss in one or both eyes is the most feared complication of this disease, but stroke and complications of large-vessel vasculitis (e.g., aortic aneurysm) can also occur in GCA [6].

Standard treatment for GCA involves immediate initiation of high-dose glucocorticoids $(40-60 \mathrm{mg} /$ day) to provide prompt relief of symptoms and avoid permanent visual impairment, followed by slow tapering of doses over many months [7-9]. Relapse is frequent, occurring in up to $82 \%$ of patients in the first year of treatment even if glucocorticoids are tapered over 52 weeks [10-13]. Disease relapse generally requires the reinstitution of high doses of glucocorticoids.

Tocilizumab (TCZ) is a humanized monoclonal antibody blocker of interleukin 6 signaling. It was approved for the treatment of rheumatoid arthritis (RA) in Europe in 2009 and in the USA in 2010 and has been approved in both intravenous and subcutaneous formulations. Recent clinical trial findings that demonstrated the efficacy of subcutaneous TCZ for treating GCA in combination with glucocorticoids led to its approval for the treatment of GCA in the USA and Europe in 2017 [13]. In the Giant-Cell Arteritis Actemra (GiACTA) trial, significantly greater proportions of patients receiving subcutaneous TCZ $162 \mathrm{mg}$ weekly or every other week concomitant with a 26 -week glucocorticoid taper sustained remission after 52 weeks of treatment compared with patients receiving placebo concomitant with either a 26or 52-week glucocorticoid taper [13].

Although the safety profile of TCZ in patients with RA is well characterized, its safety profile in patients with GCA continues to be defined. The safety profile of TCZ in patients with GCA may differ from that observed in patients with RA due to differences in the underlying disease and the patient populations as well as the higher glucocorticoid doses used to treat GCA compared with RA. Conditions associated with long-term glucocorticoid exposure, including osteoporosis, infections, cardiovascular disease, diabetes mellitus, cataracts, and glaucoma, are frequent comorbidities in patients with GCA [10, 14-17]. Thus, glucocorticoid use in patients with either GCA or RA is associated with increased risk of glucocorticoidassociated comorbidities $[18,19]$. One-half to 
two-thirds of patients with RA receive glucocorticoids [20, 21]; however, only approximately one-third of patients with RA have persistent long-term use ( $>5$ years) $[20,21]$. In contrast, per treatment guidelines, all patients with GCA are likely to receive a cumulative dose of glucocorticoids exceeding $1000 \mathrm{mg}$ during their first 4 weeks of treatment, with cumulative glucocorticoid exposure increasing as the dose is slowly tapered during periods of disease control and increased in the event of relapse [7-9].

Direct comparisons of adverse events in RA and GCA patient populations are needed to contextualize the safety profile of TCZ in patients with GCA. In this study we describe the incidence rates (IRs) of adverse events of special interest (AESI) in TCZ-naïve patients with GCA or RA in a general healthcare claims database, with the aim to examine differences in the underlying disease and glucocorticoid regimens. We also describe the IRs of AESI (AESI IRs) over a 1-year period in TCZ-treated patients with GCA or RA in the clinical development program to further define the safety profile of TCZ in GCA.

\section{METHODS}

\section{Data Source: Clinical Trial Populations}

The AESI IRs over a 1-year period (52 weeks) were calculated for patients with GCA who received TCZ in the GiACTA clinical trial (ClinicalTrials.gov number NCT01791153) and for a pooled population of patients with RA who received TCZ in 12 clinical trials (ClinicalTrials.gov numbers NCT00106548, NCT00106522, NCT00106574, NCT00106535, NCT00109408, NCT01007435, NCT01119859, NCT00810199, NCT01232569, NCT01194414, NCT01662063, NCT00720798) [13, 22-32]. AESI refer to identified and potential risks observed during the TCZ clinical trial program and include infections, hepatic events, gastrointestinal (GI) perforations, demyelinating disorders, cardiovascular events, bleeding events, and malignancies.

Patients enrolled in GiACTA met the following criteria: age $\geq 50$ years, diagnosis of new-onset or relapsing GCA, and GCA diagnosis confirmed by temporal artery biopsy and/or cross-sectional imaging. Patients enrolled in the TCZ clinical trials in RA met the following criteria: age $\geq 18$ years and active $\mathrm{RA}$ with $\geq 4$ swollen and $\geq 4$ tender joints.

This article is based on previously conducted studies and does not contain any studies with human participants or animals performed by any of the authors. The clinical trials from which data were included were conducted with informed written consent from participating patients, with the approval of the ethics committee or institutional review board for each participating study site and in accordance with the Helsinki Declaration of 1964 , as revised in 2013. The healthcare claims databases from which data were included were based on previously conducted studies that used only deidentified patient data; therefore, informed consent for this analysis was not needed.

\section{Data Source: Healthcare Claims Cohorts}

The AESI IRs in TCZ-naïve adult patients with GCA or RA were estimated from the US-based MarketScan administrative healthcare claims database from January 1, 2001, to June 30, 2015.

Patients with GCA met the following criteria: $\geq 1$ inpatient claim or $\geq 2$ outpatient claims (separated by $\geq 7$ and $\leq 365$ days) with a GCA diagnosis (International Classification of Diseases, Ninth Revision, Clinical Modification [ICD-9-CM] code 446.5); age $\geq 50$ years at the index date; $\geq 2$ prescription claims for oral glucocorticoids (the first claim $\leq 6$ months after diagnosis; the second claim $\leq 6$ months after the first); $\geq 1$ diagnostic workup claim ( $\leq 1$ year pre- or post-index) for temporal artery biopsy (Current Procedural Terminology code 37609), magnetic resonance angiography-computed tomography angiography, or positron emission tomography-computed tomography; no prior claims with a GCA diagnosis $(\leq 1$ year pre-index); $\geq 1$ claim with a GCA diagnosis after the diagnostic workup claim; continuous medical and pharmacy coverage and data available for $\geq 365$ days (30-day gap permitted only in the pre-index period); $\geq 365$ days of 
eligibility prior to the index date; no TCZ exposure within the patient's enrollment in the database; and $\geq 365$ days of follow-up after the index date and after the date of the first glucocorticoid prescription. The index date was defined as the first date of GCA diagnosis.

Patients with RA met the following criteria: $\geq 2$ outpatient confirmatory claims (separated by $\geq 7$ and $\leq 365$ days) with an RA diagnosis or $\geq 1$ inpatient confirmatory claim; age $\geq 50$ years at the index date; continuous medical and pharmacy coverage and data available for $\geq 365$ days (30-day gap permitted only in the pre-index period); $\geq 1$ prescription claim for a conventional synthetic diseasemodifying antirheumatic drug or biologic disease-modifying antirheumatic drug (adalimumab, certolizumab, etanercept, golimumab, infliximab, abatacept, tofacitinib) after the index date and during the continuous enrollment period; no concomitant rheumatologic or other immunologic conditions or GCA (defined as $\geq 2$ outpatient claims [separated by $\geq 7$ and $\leq 365$ days] or $\geq 1$ inpatient claim) before the end of the continuous enrollment period; and no TCZ exposure within the patient's enrollment in the database. The index date was defined as the first date of RA diagnosis.

\section{Statistical Analysis}

Risks for AESI among patients with GCA versus those with RA in the claims database were estimated using Poisson regression. AESI risks were adjusted for age and oral glucocorticoid use. Age was included in models as a categorical variable (with categories of 50 to $<55,55-59,60-64$, $65-69,70-74,75-79,80-84$, and $>84$ years). Oral glucocorticoid use was measured as the total cumulative dose from index to the end of follow-up and included in the models as a continuous variable. Age was explored as a continuous variable and a continuous variable squared to allow for a nonlinear form in post hoc analyses, but the adjusted risk ratios shifted the outcomes for only the AESI with large confidence intervals (CI).

\section{RESULTS}

\section{Study Populations}

From the clinical trials, 149 TCZ-treated patients with GCA and 7647 TCZ-treated patients with RA were included in this analysis (Table 1). From the healthcare claims database, 4804 TCZ-naïve patients with GCA and 15,164 TCZ-naïve patients with RA were included (Table 1). In both the clinical trials and claims-based populations, patients with GCA were older than patients with RA. The mean [standard deviation (SD)] age at baseline of patients with GCA was 69.5 (8.4) years in the GiACTA trial and $73.4(9.8)$ years in the claims cohort; the mean (SD) age at baseline in patients with RA was $52.0(12.6)$ and 60.3 (8.2) years in the clinical trial and claims cohorts, respectively. In the claims cohorts, $100 \%$ of patients with GCA were receiving glucocorticoids at baseline versus $84 \%$ of patients with RA, and the mean glucocorticoid dose at baseline was higher in patients with GCA than in patients with RA (46.9 vs. $19.0 \mathrm{mg} /$ day, respectively).

\section{AESI in TCZ-Naïve Patients With GCA or RA}

In the healthcare claims data, the AESI IRs in TCZ-naïve patients with GCA exceeded those in TCZ-naïve patients with RA (Table 2). The most frequent AESI in both the GCA and RA cohorts was serious infections, with an IR (95\% CI) of 28.86 (27.19-30.61) per 100 patient-years (PY) in the GCA cohort and $8.48(8.00-8.98)$ per $100 \mathrm{PY}$ in the RA cohort. The next most frequent AESI in the GCA cohort were stroke, malignancies, opportunistic infections, and myocardial infarction. All of these occurred at higher frequencies in the GCA cohort than in the RA cohort.

\section{AESI in TCZ-Treated Patients With GCA or RA}

The AESI IRs in TCZ-treated patients with GCA $(n=149 ; \quad$ approx. $138 \mathrm{PY})$ in the GiACTA 
Table 1 Patient demographics and clinical characteristics

\begin{tabular}{|c|c|c|c|c|}
\hline \multirow[t]{2}{*}{ Characteristic } & \multirow{2}{*}{$\begin{array}{l}\text { GiACTA clinical } \\
\text { trial } \\
\text { Patients with GCA } \\
(n=149)\end{array}$} & \multirow{2}{*}{$\begin{array}{l}\text { TCZ clinical trial } \\
\text { database } \\
\text { Patients with RA } \\
(n=7647)\end{array}$} & \multicolumn{2}{|c|}{ Healthcare claims analysis } \\
\hline & & & $\begin{array}{l}\text { Patients with GCA } \\
(n=4804)\end{array}$ & $\begin{array}{l}\text { Patients with RA } \\
(n=15,164)\end{array}$ \\
\hline TCZ exposure & Yes & Yes & No & No \\
\hline Age, mean (SD), years & $69.5(8.4)$ & $52.0(12.6)$ & $73.4(9.8)$ & $60.3(8.2)$ \\
\hline$<65$ years, $n(\%)$ & $49(33)$ & $6438(84)$ & $1096(23)$ & $11,411(75)$ \\
\hline$\geq 65$ years, $n(\%)$ & $100(67)$ & $1209(16)$ & $3708(77)$ & $3753(25)$ \\
\hline Female, $n(\%)$ & $112(85)$ & $6240(84)$ & $3425(71)$ & $10,721(71)$ \\
\hline $\begin{array}{l}\text { Disease duration, mean } \\
(\mathrm{SD}) \text {, years }\end{array}$ & $0.8(1.5)$ & $8.1(8.4)$ & $1.9(2.1)$ & $4.3(2.9)$ \\
\hline $\begin{array}{l}\text { Follow-up, mean }(\mathrm{SD}) \text {, } \\
\text { years }\end{array}$ & $0.9(0.2)$ & $2.9(1.9)$ & $3.9(3.1)$ & $4.5(2.8)$ \\
\hline $\begin{array}{l}\text { Patients receiving GCs, } \\
n(\%)\end{array}$ & $149(100)$ & $4161(54)$ & $4804(100)$ & $12,705(84)$ \\
\hline $\begin{array}{l}\text { Baseline GC dose, mean } \\
\text { (SD), mg/day }\end{array}$ & $35.0(13.5)$ & $8.6(55.5)$ & $46.9(34.8)$ & $19.0(56.1)$ \\
\hline $\begin{array}{l}\text { Cumulative GC dose, } \\
\text { mean (SD), } \mathrm{mg}^{\mathrm{b}}\end{array}$ & $2213(1467)$ & NA & $2480(4569)$ & $1329(4382)$ \\
\hline$<1000 \mathrm{mg}, n(\%)$ & $28(19)$ & NA & $228(5)$ & $6366(42)$ \\
\hline$\geq 1000 \mathrm{mg}, n(\%)$ & $121(81)$ & NA & $4576(95)$ & $8798(58)$ \\
\hline
\end{tabular}

$G C$ Glucocorticoid, $G C A$ giant cell arteritis, $N A$ not available, $R A$ rheumatoid arthritis, $T C Z$ tocilizumab

${ }^{a}$ For claims cohorts, duration was defined as the time from the index date to the last claim with a diagnosis of the disease

${ }^{b}$ For the GiACTA cohort, cumulative GC dose comprised on-study GC use (not prior GC use). For the RA clinical trials cohort, GC dose information was not fully captured in long-term extension studies. For the claims cohorts, cumulative GC dose was calculated from the index date throughout the entire follow-up period

clinical trial were different from those in TCZtreated patients with RA $(n=7647$; approx. 22,394 PY) in the pooled RA clinical trial population (Table 3 ). TCZ-treated patients in the GiACTA trial had greater IRs (95\% CI) of serious infections [7.94 (3.97-14.22) vs. 4.33 (3.86-4.84) per $100 \mathrm{PY}]$ and opportunistic infections [1.44 (0.17-5.22) vs. $0.30(0.18-0.45)$ per $100 \mathrm{PY}$ ] than did TCZ-treated patients in the pooled RA clinical trial population over 1 year. This finding was consistent with findings from the claims data on the TCZ-naive patients with GCA versus those with RA, although the IRs in the GiACTA clinical trial population were calculated based on a limited number of events.

\section{Risk of AESI in TCZ-Naïve Patients With GCA versus RA}

In the US claims data, after adjusting for age and oral glucocorticoid dose, TCZ-naïve patients with GCA were at higher risk for all AESI (with sufficient data, including serious infections, opportunistic infections, GI perforations, malignancies, myocardial infarction, and stroke) compared with TCZ-naïve patients with RA (Fig. 1). The greatest increase in risk was 
Table 2 Incidence rates of adverse events of special interest in tocilizumab-naïve patients with giant cell arteritis or rheumatoid arthritis followed for 1 year after index date in healthcare claims analyses

\begin{tabular}{|c|c|c|}
\hline AESI & $\begin{array}{l}\text { Patients with GCA } \\
(n=4804 \text {; approx. } 4804 \mathrm{PY})\end{array}$ & $\begin{array}{l}\text { Patients with RA } \\
(n=15,164 \text {; approx. } 15,164 \mathrm{PY})\end{array}$ \\
\hline \multicolumn{3}{|l|}{ Serious infections } \\
\hline No. of events & 1113 & 1174 \\
\hline Rate per 100 PY (95\% CI) & $28.86(27.19-30.61)$ & $8.48(8.00-8.98)$ \\
\hline \multicolumn{3}{|l|}{ Opportunistic infections } \\
\hline No. of events & 163 & 143 \\
\hline Rate per 100 PY (95\% CI) & $3.49(2.97-4.07)$ & $0.96(0.81-1.13)$ \\
\hline \multicolumn{3}{|l|}{ Serious hepatic events } \\
\hline No. of events & 6 & 15 \\
\hline Rate per 100 PY (95\% CI) & $0.13(0.05-0.27)^{\mathrm{a}}$ & $0.10(0.06-0.16)$ \\
\hline \multicolumn{3}{|l|}{ Demyelinating disorders } \\
\hline No. of events & 31 & 3 \\
\hline Rate per 100 PY (95\% CI) & $0.65(0.44-0.93)$ & $0.02(0.004-0.06)$ \\
\hline \multicolumn{3}{|l|}{ GI perforations } \\
\hline No. of events & 26 & 16 \\
\hline Rate per 100 PY (95\% CI) & $0.55(0.36-0.80)$ & $0.11(0.06-0.17)$ \\
\hline \multicolumn{3}{|l|}{ Malignancies $^{\mathrm{b}}$} \\
\hline No. of events & 176 & 223 \\
\hline Rate per 100 PY (95\% CI) & $4.07(3.49-4.72)$ & $1.54(1.35-1.76)$ \\
\hline \multicolumn{3}{|l|}{ Myocardial infarction } \\
\hline No. of events & 113 & 124 \\
\hline Rate per 100 PY (95\% CI) & $2.41(1.99-2.90)$ & $0.83(0.69-0.99)$ \\
\hline \multicolumn{3}{|l|}{ Stroke } \\
\hline No. of events & 211 & 77 \\
\hline Rate per 100 PY (95\% CI) & $4.63(4.02-5.30)$ & $0.51(0.40-0.64)$ \\
\hline
\end{tabular}

$A E S I$ adverse events of special interest, $G I$ gastrointestinal, $P Y$ patient-years, $R A$ rheumatoid arthritis

a Includes acute hepatic failure and hepatic transplant

${ }^{b}$ Includes non-melanoma skin cancer

observed for stroke and GI perforations in TCZnaïve patients with GCA versus those with RA, with risk ratios $(95 \% \mathrm{CI})$ of $5.41(3.65-8.01)$ and 4.44 (1.61-12.24), respectively.

\section{DISCUSSION}

Our analysis showed that tocilizumab-naïve patients with GCA from the healthcare claims database had higher AESI IRs than did TCZ- 
Table 3 Incidence rates of adverse events of special interest in tocilizumab-treated patients with with giant cell arteritis or rheumatoid arthritis in clinical trial populations over 1 year

\begin{tabular}{|c|c|c|}
\hline AESI & $\begin{array}{l}\text { GiACTA clinical trial patients } \\
\text { with GCA }(n=149 ; 138 \text { PY })\end{array}$ & $\begin{array}{l}\text { TCZ pooled clinical trial population } \\
\text { with RA }(n=7647 ; 7071 \mathrm{PY})\end{array}$ \\
\hline \multicolumn{3}{|l|}{ Serious infections } \\
\hline Patients with $\geq 1$ event, $n$ (\%) & $9(6.0)$ & $277(3.6)$ \\
\hline Rate per 100 PY (95\% CI) & $7.94(3.97-14.22)$ & $4.33(3.86-4.84)$ \\
\hline \multicolumn{3}{|l|}{ Opportunistic infections } \\
\hline Patients with $\geq 1$ event, $n$ (\%) & $1(0.7)$ & $21(0.3)$ \\
\hline Rate per 100 PY (95\% CI) & $1.44(0.17-5.22)$ & $0.30(0.18-0.45)$ \\
\hline \multicolumn{3}{|l|}{ Serious hepatic events } \\
\hline Patients with $\geq 1$ event, $n$ (\%) & 0 & $1(0.0)$ \\
\hline Rate per 100 PY (95\% CI) & $0.00(0.00-2.66)$ & $0.01(0.02-0.08)^{\mathrm{a}}$ \\
\hline \multicolumn{3}{|l|}{ Demyelinating disorders } \\
\hline Patients with $\geq 1$ event, $n(\%)$ & 0 & $1(0.0)$ \\
\hline Rate per 100 PY (95\% CI) & $0.00(0.00-2.66)$ & $0.01(0.00-0.08)$ \\
\hline \multicolumn{3}{|l|}{ GI perforations } \\
\hline Patients with $\geq 1$ event, $n$ (\%) & 0 & $9(0.1)$ \\
\hline Rate per 100 PY (95\% CI) & $0.00(0.00-2.66)$ & $0.14(0.07-0.26)^{\mathrm{b}}$ \\
\hline \multicolumn{3}{|l|}{ Malignancies $^{c}$} \\
\hline Patients with $\geq 1$ event, $n(\%)$ & $1(0.7)$ & $75(1.0)$ \\
\hline Rate per 100 PY (95\% CI) & $0.72(0.02-4.02)$ & $1.09(0.86-1.36)^{\mathrm{b}}$ \\
\hline \multicolumn{3}{|l|}{ Myocardial infarction } \\
\hline Patients with $\geq 1$ event, $n$ (\%) & 0 & $29(0.4)$ \\
\hline Rate per 100 PY (95\% CI) & $0.00(0.00-2.66)$ & $0.41(0.27-0.59)$ \\
\hline \multicolumn{3}{|l|}{ Stroke } \\
\hline Patients with $\geq 1$ event, $n$ (\%) & $1(0.7)$ & \\
\hline Rate per 100 PY (95\% CI) & $0.72(0.02-4.02)$ & \\
\hline \multicolumn{3}{|l|}{ Serious bleeding events } \\
\hline Patients with $\geq 1$ event, $n$ (\%) & 0 & \\
\hline Rate per 100 PY (95\% CI) & $0.00(0.00-2.66)$ & \\
\hline
\end{tabular}

$A E S I$ adverse events of special interest, $G C A$ giant cell arteritis, $G I$ gastrointestinal, $P Y$ patient-years, $R A$ rheumatoid arthritis, $T C Z$ tocilizumab

${ }^{a}$ Includes serious hepatic events with preferred terms contained in the Hepatic Failure, Fibrosis, and Cirrhosis and Other Liver Damage-Related Conditions Standardized MedDRA Queries (SMQ) Wide and Hepatitis, Non-Infectious SMQ Wide

b Events of malignancies and GI perforations were medically confirmed

${ }^{c}$ Includes non-melanoma skin cancer 


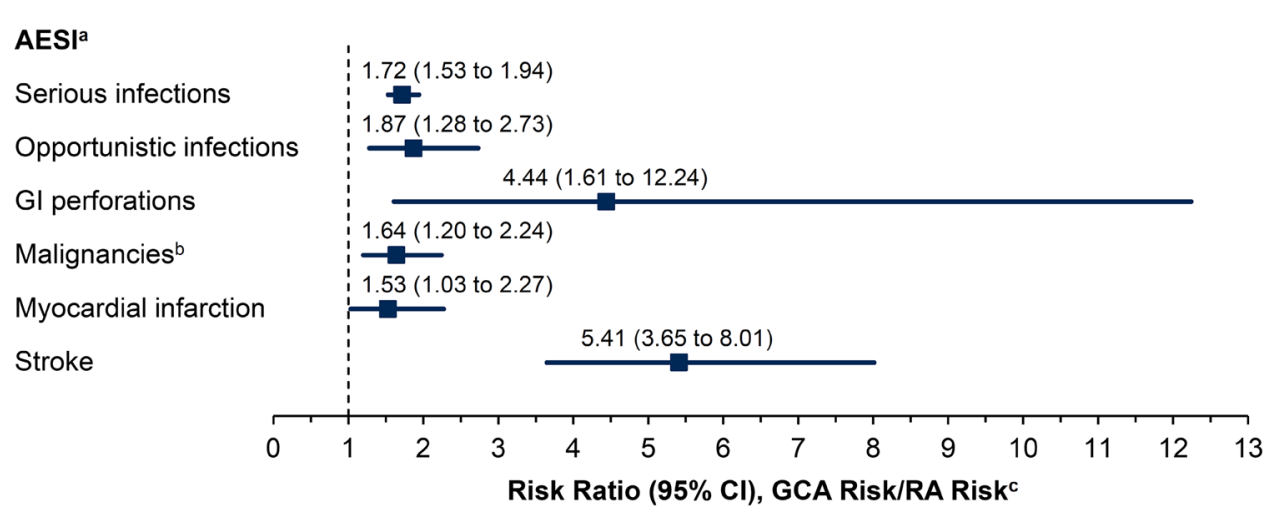

Fig. 1 Risk of adverse events of special interest (AESI) in tocilizumab-naïve patients with giant cell arteritis $(G C A)$ versus those with rheumatoid arthritis $(R A)$ followed for 1 year after index date in healthcare claims analyses. Filled squares represent the risk ratio, bars represent the 95\% confidence interval $(C I)$. GI Gastrointestinal. ${ }^{\text {a }}$ Risk ratios

naïve patients with RA. Analysis of the claims data revealed that the IRs for serious infections, opportunistic infections, demyelinating disorders, GI perforations, malignancies, myocardial infarction, and stroke were at least threefold greater in patients with GCA than in patients with RA. Serious hepatic events occurred with similar IRs in both claims cohorts; however, the low number of events limited any comparison. Clinical trial data for TCZ in patients with RA or GCA reflect these findings, although the number of events and exposure in TCZ-treated patients with GCA are limited. Together, these findings suggest differences in the underlying disease burden associated with RA versus GCA.

The use of higher doses and longer courses of glucocorticoids in patients with GCA versus those with RA appears to influence the AESI IRs in both TCZ-naïve and TCZ-treated patients. These results reflect the finding that patients with GCA have an increased risk of glucocorticoidrelated adverse events with each 1-g increase in glucocorticoid exposure [18, 33]. Similarly, nested case-control analyses indicate that patients with GCA receiving high average daily doses of oral prednisolone $(30 \mathrm{mg} /$ day) are at increased risk of glucocorticoid-related adverse events compared with those receiving low average daily doses (5 mg/day) [16]. Consistent with the known burden of comorbidities were not calculated for the AESI of hepatic events, demyelinating disorders, or serious bleeding events due to insufficient data ( $\leq 10$ events in 1 group). ${ }^{\mathrm{b}}$ Includes nonmelanoma skin cancer. ${ }^{c}$ Adjusted for age and oral glucocorticoid dose

associated with long-term glucocorticoid exposure, in this study we observed greater risks of serious and opportunistic infections, myocardial infarction, and stroke in TCZ-naïve patients with GCA versus TCZ-naive patients with RA [10, 14-17].

Patients with GCA or RA alike are at increased risk of cardiovascular disease compared with the age-matched general population [34-37]. In the healthcare claims cohorts, an elevated risk of myocardial infarction was observed in TCZ-naïve patients with GCA compared with patients with RA. This finding was consistent with a claims-based study of Canadian patients with GCA that found a significantly greater incidence of myocardial infarction in their patient population than in the age- and sex-matched general population [38]. A major risk factor for cardiovascular disease is age, and patients with GCA identified in the claims data or enrolled in the GiACTA trial were notably older than patients with RA in either the claims or clinical trial cohorts (mean age 69.5-73.4 vs. 52.0-60.3 years, respectively). The use of oral glucocorticoids is also a risk factor for cardiovascular disease [39, 40]. In the claims cohorts, patients with GCA had a nearly twofold greater cumulative glucocorticoid dose than patients with RA over the full study followup period. Prospective studies on patients with 
GCA are needed to distinguish the contributions of age, glucocorticoid exposure, and underlying inflammatory disease state on cardiovascular risks in this patient population.

In the GiACTA trial, AESI IRs were similar between the TCZ and placebo groups [13]. Together with the findings of this study, this result supports the hypothesis that the risk of AESI in TCZ-treated patients with GCA is more strongly influenced by the disease itself and treatment with glucocorticoids than it is by TCZ treatment.

This study has some important limitations. Data in patients with GCA treated with TCZ were available from a single trial (GiACTA), representing a smaller population and lower total exposure (in PY) compared with the TCZtreated RA cohort. TCZ was approved to treat GCA only recently, in 2017; thus, postmarketing data are not yet available in sufficient quantity for analysis, but these will be a focus of future real-world studies. Claims data provide an incomplete picture of health research: clinical data points are not typically collected, few patient demographic variables are available, and outcomes important for reimbursement are likely to be overrepresented due to the databases' design to function for medical billing. The MarketScan data comprise commercially insured individuals only and only claims from large employers, creating a non-random sample of patients who have access to commercial insurance. The time periods and duration of the total follow-up were different in the clinical trial and claims data included in this analysis; however, both claims cohorts overlapped in time with the clinical trials. Therefore, these findings should be interpreted cautiously.

\section{CONCLUSIONS}

In clinical practice, the expectation may exist that the pattern of TCZ-related adverse events will be different in patients with GCA than in those with RA. In this study, the frequencies of AESI were indeed different, but the observed differences largely align with the expected differences based on the increased age and greater glucocorticoid exposure in patients with GCA versus those with RA. Future analyses are needed to determine how differences in patient demographics may further differentiate the safety profile of TCZ between patients with RA and those with GCA. Long-term prospective studies will provide additional characterization of TCZ's safety in the GCA population.

\section{ACKNOWLEDGEMENTS}

Funding. This study was funded by F. Hoffmann-La Roche Ltd and Genentech, Inc. Article processing charges were funded by F. Hoffmann-La Roche Ltd. All authors had full access to all of the data in this study and take complete responsibility for the integrity of the data and accuracy of the data analysis.

Medical Writing, Editorial, and Other Assistance. Support for third-party writing assistance for this manuscript, furnished by Benjamin L. Ricca, PhD, of Health Interactions, Inc, was provided by F. Hoffmann-La Roche, Ltd.

Authorship. All named authors meet the International Committee of Medical Journal Editors (ICMJE) criteria for authorship for this article, take responsibility for the integrity of the work as a whole, and have given their approval for this version to be published.

Disclosures. Sara Gale is an employee of Genentech, Inc. Huong Trinh is an employee of Genentech, Inc. Katie Tuckwell is an employee of Genentech, Inc. Neil Collinson is an employee of Roche Products Ltd. John H. Stone has received consulting fees and research grants from Roche Pharmaceuticals. Khaled Sarsour is an employee of Genentech, Inc. Jinglan Pei is an employee of Genentech, Inc. Jennie Best is an employee of Genentech, Inc. Christine Birchwood was an employee of Genentech, Inc., South San Francisco, California, USA at the time of the study, and is currently affiliated with Aimmune Therapeutics, Brisbane, California, USA. Shalini V. Mohan is an employee of Genentech, Inc. 
Compliance with Ethics Guidelines. This article is based on previously conducted studies and does not contain any studies with human participants or animals performed by any of the authors. The clinical trials from which data were included were conducted with informed written consent from participating patients, with the approval of the ethics committee or institutional review board for each participating study site and in accordance with the Helsinki Declaration of 1964, as revised in 2013. The healthcare claims databases from which data were included were based on previously conducted studies and used only de-identified patient data; therefore, informed consent for this analysis was not needed.

Data Availability. The datasets analyzed in this study are available from the corresponding author on reasonable request.

Open Access. This article is distributed under the terms of the Creative Commons Attribution-NonCommercial 4.0 International License (http://creativecommons.org/licenses/ by-nc/4.0/), which permits any noncommercial use, distribution, and reproduction in any medium, provided you give appropriate credit to the original author(s) and the source, provide a link to the Creative Commons license, and indicate if changes were made.

\section{REFERENCES}

1. Hunder GG, Bloch DA, Michel BA, et al. The American College of Rheumatology 1990 criteria for the classification of giant cell arteritis. Arthritis Rheum. 1990;33:1122-8.

2. Mukhtyar C, Guillevin L, Cid MC, et al. EULAR recommendations for the management of large vessel vasculitis. Ann Rheum Dis. 2009;68:318-23.

3. Lawrence RC, Felson DT, Helmick CG, et al. Estimates of the prevalence of arthritis and other rheumatic conditions in the United States. Part II. Arthritis Rheum. 2008;58:26-35.

4. Gabriel SE, Michaud K. Epidemiological studies in incidence, prevalence, mortality, and comorbidity of the rheumatic diseases. Arthritis Res Ther. 2009;11:229.
5. Chandran AK, Udayakumar PD, Crowson CS, Warrington KJ, Matteson EL. The incidence of giant cell arteritis in Olmsted county, Minnesota, over a 60-year period 1950-2009. Scand J Rheumatol. 2015;44:215-8.

6. Gonzalez-Gay MA, Castaneda S, Llorca J. Giant cell arteritis: visual loss is our major concern. J Rheumatol. 2016;43:1458-61.

7. Fraser JA, Weyand CM, Newman NJ, Biousse V. The treatment of giant cell arteritis. Rev Neurol Dis. 2008;5:140-52.

8. Warrington KJ, Matteson EL. Management guidelines and outcome measures in giant cell arteritis (GCA). Clin Exp Rheumatol. 2007;25:137-41.

9. Dasgupta B, Borg FA, Hassan N, et al. BSR and BHPR guidelines for the management of giant cell arteritis. Rheumatology (Oxford). 2010;49:1594-7.

10. Proven A, Gabriel SE, Orces C, O'Fallon WM, Hunder GG. Glucocorticoid therapy in giant cell arteritis: duration and adverse outcomes. Arthritis Rheum. 2003;49:703-8.

11. Andersson R, Malmvall BE, Bengtsson BA. Longterm corticosteroid treatment in giant cell arteritis. Acta Med Scand. 1986;220:465-9.

12. Labarca C, Koster MJ, Crowson CS, et al. Predictors of relapse and treatment outcomes in biopsy-proven giant cell arteritis: a retrospective cohort study. Rheumatology (Oxford). 2016;55:347-56.

13. Stone JH, Tuckwell K, Dimonaco S, et al. Trial of tocilizumab in giant-cell arteritis. $\mathrm{N}$ Engl J Med. 2017;377:317-28.

14. Petri H, Nevitt A, Sarsour K, Napalkov P, Collinson $\mathrm{N}$. Incidence of giant cell arteritis and characteristics of patients: data-driven analysis of comorbidities. Arthritis Care Res (Hoboken). 2015;67:390-5.

15. Durand $M$, Thomas SL. Incidence of infections in patients with giant cell arteritis: a cohort study. Arthritis Care Res (Hoboken). 2012;64:581-8.

16. Wilson JC, Sarsour K, Collinson N, et al. Serious adverse effects associated with glucocorticoid therapy in patients with giant cell arteritis (GCA): a nested case-control analysis. Semin Arthritis Rheum. 2017;46:819-27.

17. Tuckwell K, Collinson N, Dimonaco S, et al. Newly diagnosed vs. relapsing giant cell arteritis: baseline data from the GiACTA trial. Semin Arthritis Rheum. 2017;46:657-64.

18. Gale S, Wilson JC, Chia J, et al. Risk associated with cumulative oral glucocorticoid use in patients with 
giant cell arteritis in real-world databases from the USA and UK. Rheumatol Ther. 2018. https://doi. org/10.1007/s40744-018-0112-8.

19. Wilson JC, Sarsour K, Gale S, Petho-Schramm A, Jick SS, Meier CR. Incidence and risk of glucocorticoid-associated adverse effects in patients with rheumatoid arthritis. Arthritis Care Res (Hoboken). 2018. https://doi.org/10.1002/acr.23611.

20. Caplan L, Wolfe F, Russell AS, Michaud K. Corticosteroid use in rheumatoid arthritis: prevalence, predictors, correlates, and outcomes. J Rheumatol. 2007;34:696-705.

21. Best JH, Kong AM, Lenhart GM, Sarsour K, StottMiller M, Hwang Y. Association between glucocorticoid exposure and healthcare expenditures for potential glucocorticoid-related adverse events in patients with rheumatoid arthritis. J Rheumatol. 2018;45:320-8.

22. Smolen JS, Beaulieu A, Rubbert-Roth A, et al. Effect of interleukin-6 receptor inhibition with tocilizumab in patients with rheumatoid arthritis (OPTION study): a double-blind, placebo-controlled, randomised trial. Lancet. 2008;371:987-97.

23. Emery P, Keystone E, Tony HP, et al. IL-6 receptor inhibition with tocilizumab improves treatment outcomes in patients with rheumatoid arthritis refractory to anti-tumour necrosis factor biologicals: results from a 24-week multicentre randomised placebo-controlled trial. Ann Rheum Dis. 2008;67:1516-23.

24. Genovese MC, McKay JD, Nasonov EL, et al. Interleukin-6 receptor inhibition with tocilizumab reduces disease activity in rheumatoid arthritis with inadequate response to disease-modifying antirheumatic drugs: the tocilizumab in combination with traditional disease-modifying antirheumatic drug therapy study. Arthritis Rheum. 2008;58:2968-80.

25. Kremer JM, Blanco R, Brzosko M, et al. Tocilizumab inhibits structural joint damage in rheumatoid arthritis patients with inadequate responses to methotrexate: results from the double-blind treatment phase of a randomized placebo-controlled trial of tocilizumab safety and prevention of structural joint damage at one year. Arthritis Rheum. 2011;63:609-21.

26. Jones G, Sebba A, Gu J, et al. Comparison of tocilizumab monotherapy versus methotrexate monotherapy in patients with moderate to severe rheumatoid arthritis: the AMBITION study. Ann Rheum Dis. 2010;69:88-96.

27. Burmester GR, Rubbert-Roth A, Cantagrel A, et al. A randomised, double-blind, parallel-group study of the safety and efficacy of subcutaneous tocilizumab versus intravenous tocilizumab in combination with traditional disease-modifying antirheumatic drugs in patients with moderate to severe rheumatoid arthritis (SUMMACTA study). Ann Rheum Dis. 2014;73:69-74.

28. Dougados $M$, Kissel $K$, Sheeran $T$, et al. Adding tocilizumab or switching to tocilizumab monotherapy in methotrexate inadequate responders: 24-week symptomatic and structural results of a 2-year randomised controlled strategy trial in rheumatoid arthritis (ACT-RAY). Ann Rheum Dis. 2013;72:43-50.

29. Kivitz A, Wallace T, Olech E, et al. Long-term safety and efficacy of subcutaneously administered tocilizumab for adult rheumatoid arthritis: a multicenter phase $3 \mathrm{~b}$ long-term extension study. Rheumatol Ther. 2016;3:291-304.

30. Kivitz A, Olech E, Borofsky M, et al. Subcutaneous tocilizumab versus placebo in combination with disease-modifying antirheumatic drugs in patients with rheumatoid arthritis. Arthritis Care Res (Hoboken). 2014;66:1653-61.

31. Burmester GR, Rigby WF, van Vollenhoven RF, et al. Tocilizumab in early progressive rheumatoid arthritis: FUNCTION, a randomised controlled trial. Ann Rheum Dis. 2016;75:1081-91.

32. Gabay C, Emery P, van Vollenhoven R, et al. Tocilizumab monotherapy versus adalimumab monotherapy for treatment of rheumatoid arthritis (ADACTA): a randomised, double-blind, controlled phase 4 trial. Lancet. 2013;381:1541-50.

33. Broder MS, Sarsour K, Chang E, et al. Corticosteroid-related adverse events in patients with giant cell arteritis: a claims-based analysis. Semin Arthritis Rheum. 2016;46:246-52.

34. Avina-Zubieta JA, Choi HK, Sadatsafavi M, Etminan M, Esdaile JM, Lacaille D. Risk of cardiovascular mortality in patients with rheumatoid arthritis: a meta-analysis of observational studies. Arthritis Rheum. 2008;59:1690-7.

35. Ray JG, Mamdani MM, Geerts WH. Giant cell arteritis and cardiovascular disease in older adults. Heart. 2005;91:324-8.

36. Le Page L, Duhaut P, Seydoux D, et al. Incidence of cardiovascular events in giant cell arteritis: preliminary results of a prospective double cohort study (GRACG). Rev Med Interne. 2006;27:98-105.

37. Ursum J, Nielen MM, Twisk JW, et al. Increased risk for chronic comorbid disorders in patients with inflammatory arthritis: a population based study. 
BMC Fam Pract. 2013;14:199. doi: https://doi.org/ 10.1186/1471-2296-14-199.

38. Amiri N, De Vera M, Choi HK, Sayre EC, AvinaZubieta JA. Increased risk of cardiovascular disease in giant cell arteritis: a general population-based study. Rheumatology (Oxford). 2016;55:33-40.

39. Souverein PC, Berard A, Van Staa TP, et al. Use of oral glucocorticoids and risk of cardiovascular and cerebrovascular disease in a population based casecontrol study. Heart. 2004;90:859-65.

40. Wei L, MacDonald TM, Walker BR. Taking glucocorticoids by prescription is associated with subsequent cardiovascular disease. Ann Intern Med. 2004;141:764-70. 